\title{
Development of an Interactive Hausa Language Learning System
}

\author{
Safiriyu Eludiora \\ Obafemi Awolowo University \\ Ile-Ife, Osun State \\ Nigeria
}

\author{
Ruth Oluchi Nwokocha \\ Obafemi Awolowo University \\ Ile-Ife, Osun State \\ Nigeria, West Africa
}

\begin{abstract}
A Hausa language interactive learning system was developed for the training of beginners, foreigners and other people interested in Hausa language. Hausa language is the second most spoken language in Africa and one of the most popular among the indigenous languages in Nigeria. However, it has shortage of digital tools as well as interactive learning systems. This has necessitated the need for the development of such learning tool to mitigate extinction of the language. It also encapsulates a review of language learning systems other than the traditional classroom platforms. The simplicity of the implementation of the system allows for easy communication between users and the system. This paper presents the structure and implementation of a Hausa Interactive learning system to enhance learning the Hausa language basics electronically.
\end{abstract}

\section{General Terms}

This paper seek to save the possible extinction of the African Indigenous language and hence be categorized as an indigenous Nigerian language salvage material.

\section{Keywords}

Hausa Language, interactive learning, E-learning language learning.

\section{INTRODUCTION}

Learning new language is a time-consuming task. If the much related languages and language savants are set aside, achieving even just an intermediate level in any language requires at least a few hundred hours, and in many cases the numbers are much higher.

Both the learning time and the ultimate achievement vary much more in second language learning than in first language acquisition. This suggests that the

Choice of learning strategy is important. There is no consensus about the proper strategy of learning foreign languages, and the diversity of approaches that have been proposed makes it very unlikely that there is one way of learning that is unconditionally better than others.

Electronic learning (E-learning) has turned out to be one of the methods of learning used for educational purposes through the use of electronic devices [1].

Digital media are an interesting hybrid of the properties of oral language and of written language. Oral language is interactive but ephemeral (sound passes away quickly). It does not travel accurately because each person in a chain of communication can easily change it. Literacy is less interactive but permanent, it travels far and wide and it is harder to change as pieces of paper or books are passed through a chain of people but when digital medium carry language, language can be interactive [2].

Interactivity across the many fields concerned with interactivity, including information science, computer science, human-computer interaction, communication, and industrial design. There is little agreement over the meaning of the term interactivity [3].

Interactive learning system enable learners to acquire knowledge about concepts through direct visual, physical and mental interactions with the text book objects (may be black $\&$ white patterns or text book pictures) or may be with digital objects.

\subsection{Interactive Learning System (ILS)}

Language learners are different and approach language learning tasks differently. Some, for example, require more help than others while others are more self-motivated and require less direction and classroom support. Language learning itself is a problematic term, but it may be expressed as a way of interacting with the world [4] and as an active process of constructing knowledge rather than just acquiring it.

While it may be argued that all learning is interactive in one way or another, the term "interactive" is the presence of a "computer" with a significant role in the learning environment being studied.

Interactive Learning Systems (ILSs) are computer-based tools aimed to assist learners in various ways. They may for example, help learners to become more flexible in their learning, allow them to adapt instructions to better suit their requirements or expand their interaction beyond the lecture or tutorial [5]. It may also be the case that an ILS will encourage learners to process information actively, provide access to learning resources and allow learners to interact synchronously and asynchronously in collaborative and distributed based environments [6]

\subsubsection{The Components of Interactive Learning System}

It is important at this stage to highlight certain issues relating to an interactive learning system. Essentially, such a system is composed of five essential knowledge components or elements:

1. Content: this includes subject material, items to be taught, course aims and objectives, and skills to be developed.

2. Learners: this includes considerations about individual differences in the learner (e.g. gender, prior knowledge, age, special needs) and their 
preferred style(s) of learning (e.g. Visual/verbal, sequential, global).

3. Technology: this includes considerations about the media through which information can be delivered and multimedia representation to accommodate different types of teaching and learning styles.

4. Pedagogy: this includes methods and styles of teaching relevant to the subject matter, aims and objectives, and different learning styles of the learners. It can be argued that the wider the range of strategies included the more effective and efficient the teaching will be.

5. Interaction: this component coordinates and balances the other four elements. It concerns how the learner interacts with the computer system, the design of the interface between these, presentation of multimedia considerations and decisions about interactivity level, interaction, and consideration of the teaching styles to be used according to content and learner.

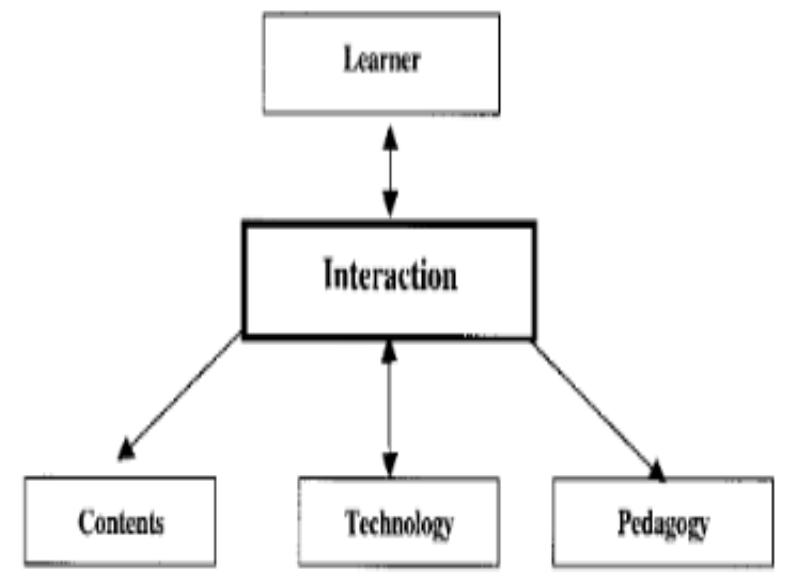

Figure 1: Components of an interactive learning system (ILS)

\subsection{Computer Assisted Language Learning (CALL)}

The new possibilities for creating language learning software tools are researched within the field of computer-assisted language learning (CALL). The advance in technology allows for creation of tools that can adapt to the learner to a much higher degree than before. How such user adaptations can be practically achieved is an area of ongoing research in CALL. Computer-assisted language learning (CALL), also called technology enhanced language learning.

An important distinction within CALL is that of the difference between CALL tutors and CALL tools. Tutors are standalone programs which directly aim at language teaching, while tools may be more general purpose according to Levy and Stockwell [7].

Levy and Stockwell (Op.Cit) describe tools as "enabling" devices, and give two groups of tools as examples: those related to computer-mediated communication (CMC) which enable better communication with other learners and native speakers of the language, and those that facilitate access to language corpora and dictionaries of various sorts. One of the advantages of tools over tutors is that they can be easily adapted to various learning styles and promote the independence of the learner. Tutors, on the other hand, have some pre-defined syllabus (Op.Cit).

\subsection{Review of Hausa Language}

Hausa (Yaren Hausa or Harshen Hausa) is the Chadic language (a branch of the Afro-Asiatic language family) with about 39 million speakers. It is spoken mainly in northern Nigeria and Niger, and also in Benin, Burkina Faso, Cameroon, Chad, Congo, Eritrea, Germany, Ghana, Sudan and Togo. Since the beginning of the 17th century, Hausa has been written with a version of the Arabic script known as
Ajami. Most of the early writing in Hausa was Islamic poetry or on Islamic themes. Ajami is still used mainly to write poetry but also for at least one newspaper and some books. There is no standard spelling system for Hausa written with the Arabic script so there is some variation in spelling between different writers [8]. The written Hausa language has 23 letters of the alphabet, 5 phonetic vowel sounds which can be either short or long, giving a total of ten (10) monophthongs. In addition, there are four (4) joint vowels (diphthongs), giving a total number of fourteen (14) vowel phonemes and also has 10 numerals [9].

\section{RELATED WORK}

Lawaly and Naroua [10] designed a spell corrector for the Hausa language. The spell

Corrector both detects spelling errors and seeks for the most likely correct words.

They used existing techniques for other languages and adapted them to the special case of the Hausa language. The corrector designed operates essentially on Mijinguini's dictionary and characteristics of the Hausa alphabet. After a brief review on spell checking and spell correcting techniques and the state of art in the Hausa language processing, they opted for the data structures trie and hash table to represent the dictionary

The corrector LySpell resulting from this study uses only a dictionary as language resource and the alphabet of Hausa language. However, it was designed and implemented so that it can also be used for other languages. The specificities of the Hausa and other African languages are efficiently handled.

Michał Kosek developed an intelligent tutoring system for Chinese language with a cognitive model learner. The designed system contains a hierarchically structured intelligent Tutoring system with two layers: the client contains 
a simple dialogue system that presents exercises to the user and provides feedback, while the server performs cognitive modeling and selects exercises.

The implementation has an English name Chinese in Context, and a Chinese name 上 文中 文 (shàng-xià-wén zhōng-wén, "context Chinese" when translated word-byword, "up-downlanguage middle-language" when translated character-by character). There are three main components: client, server and database. The character test is a supplementary component that works on the server side and interacts with the user before the main client is run. The system was written in Haskell [11] and the SQLite database1 was accessed using SQL (ISO 1992). Since Chinese in Context is a web application, the client code had to be compiled into JavaScript, in order to be executed by web browsers [12].

\section{INTERACTIVE HAUSA LANGUAGE LEARNING SYSTEM}

The interactive Hausa learning system is a beginner's, user friendly elementary learning application which allows the user to learn the alphabet and numerals of the language. This will be useful to primary and secondary schools as it has proved that languages are better learned at younger years of one's life than in adult ages when it's a little bit harder to pick up foreign languages.

The familiar mantra that children immersed in a language "soak it up like a sponge", while adults apparently do not, is not in itself proof of the existence of a critical period for language learning. But it is both easier and more important for children to quickly become good in a second language they hear spoken around them.

There are many reasons for this. Children can spend more time and effort on learning than adults who have many competing demands; the motivation for children to fit in is much higher, and the habits of pronunciation and grammar of their first language are less deeply ingrained and thus easier to overcome. And, of course, all learning gets harder with age.
Most people who decide to learn a new language are either fresh out of school or too busy to sit in a classroom in a regular basis. What this Hausa language learning system offers is the type of flexibility that allows people to learn without having to sacrifice certain aspects of their life, i.e. work or caring for family. Most language learning programs these days, especially those packages offered online, are designed specifically to allow people to study at their convenience and this project seeks to offer same.

The Hausa interactive learning is a desktop application that can be deployed on the personal computers of both individual learners as well as corporate personal computers as of a school.

The Hausa learning system will promote easy use of the system with little or no help. These will increase and influence student-centered learning, where learners create their own learning experiences. These apparent advantages have motivated this project.

The Hausa Interactive learning system was implemented with the Python programming language and followed the preliminary thinking to actualize the objective as determined. The use case diagrams of the Hausa Interactive learning system depict the two (2) major actors which are the user (also known as the learner) and the administrator use cases as well as their relationships and/or their interactions. This single use case diagram as shown in figure 2 captures the particular functionality of the Hausa Interactive learning system.

The actors in this system include;

* User : the use cases used by the user includes to log in, select letter, search for words

* Administrator: the use case used by the administrator includes updating the system and maintaining the system.

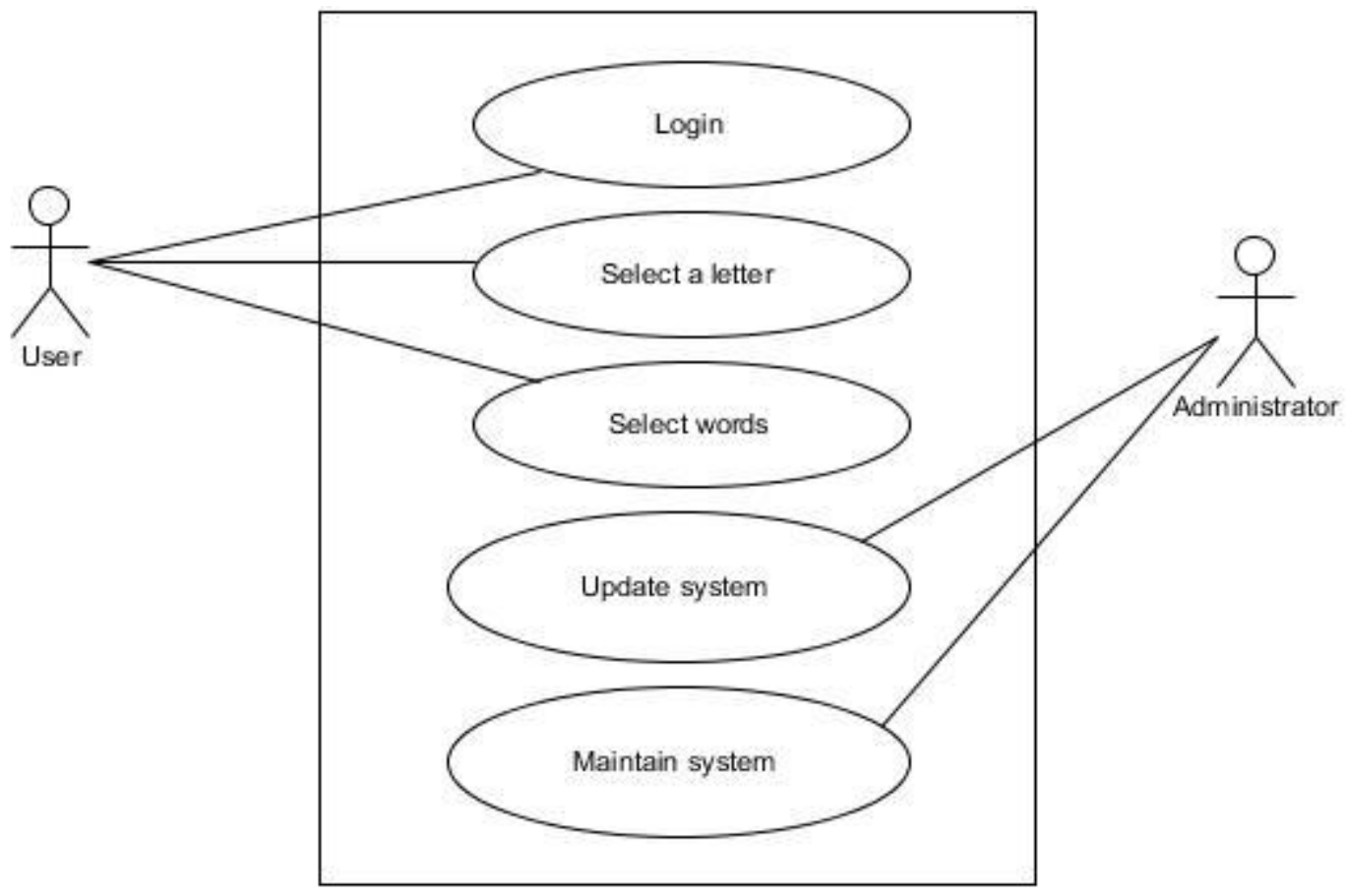

Figure 2: Use case for the Hausa learning system 


\subsection{Database Design}

A database was used to store and collect information for the Hausa interactive learning system. This database design is based on the relational database approach, in which all the tables are linked together with one relationship either as a primary key or as a foreign key. The database for this application stores all the words and numerals of both the source language (English) and the target language (Hausa) required by the system. The system has two (2) tables and also stores the image name as well as the storage location of the image in the image field of the database. Each letter of the alphabet in the database has a unique identification and each letter is matched with each word starting with that letter and matched with the stored name of each image for that letter. The design of the database was done using SQLite in the Pycharm Interactive Development Environment. Table 1 below depicts the corpus in the Hausa interactive learning system database.

\subsection{Software Design}

This is a detailed account of the modules which describe the functions of the Hausa Interactive learning system. It helps in determining the optimum size of programs modules, the complexity of data structures and the format of interface definition. The design of this system was done using Unified Modeling Language (UML).

The class diagram of the Hausa Interactive learning system shows how the different entities (Learner, Hausa database and Administrator) relate to each other; in other words, it shows the static structures of the system. The figure 3 depicts the relationship between the learner class, the administrator and the Hausa database class.

Table 1. Hausa language corpus

\begin{tabular}{|c|c|c|}
\hline $\mathrm{S} / \mathrm{N}$ & HAUSA & ENGLISH \\
\hline 1 & ÀBINCÎN & FOOD \\
\hline 2 & ÀBŌKI & FRIEND \\
\hline 3 & $\overline{\mathrm{A} D A L C \bar{I}}$ & JUSTICE \\
\hline 4 & ÀDDĀ & MACHETE \\
\hline 5 & ÀGOGO & CLOCK \\
\hline 6 & ÀGWÀGWÂ & DUCK \\
\hline 7 & ÀKWĪYĀ & GOAT \\
\hline 8 & ÀLAYYÀHŌ & SPINACH \\
\hline 9 & ÀLBASĀ & ONIONS \\
\hline 10 & $\bar{A} L \bar{E} W \bar{A}$ & CANDY \\
\hline
\end{tabular}

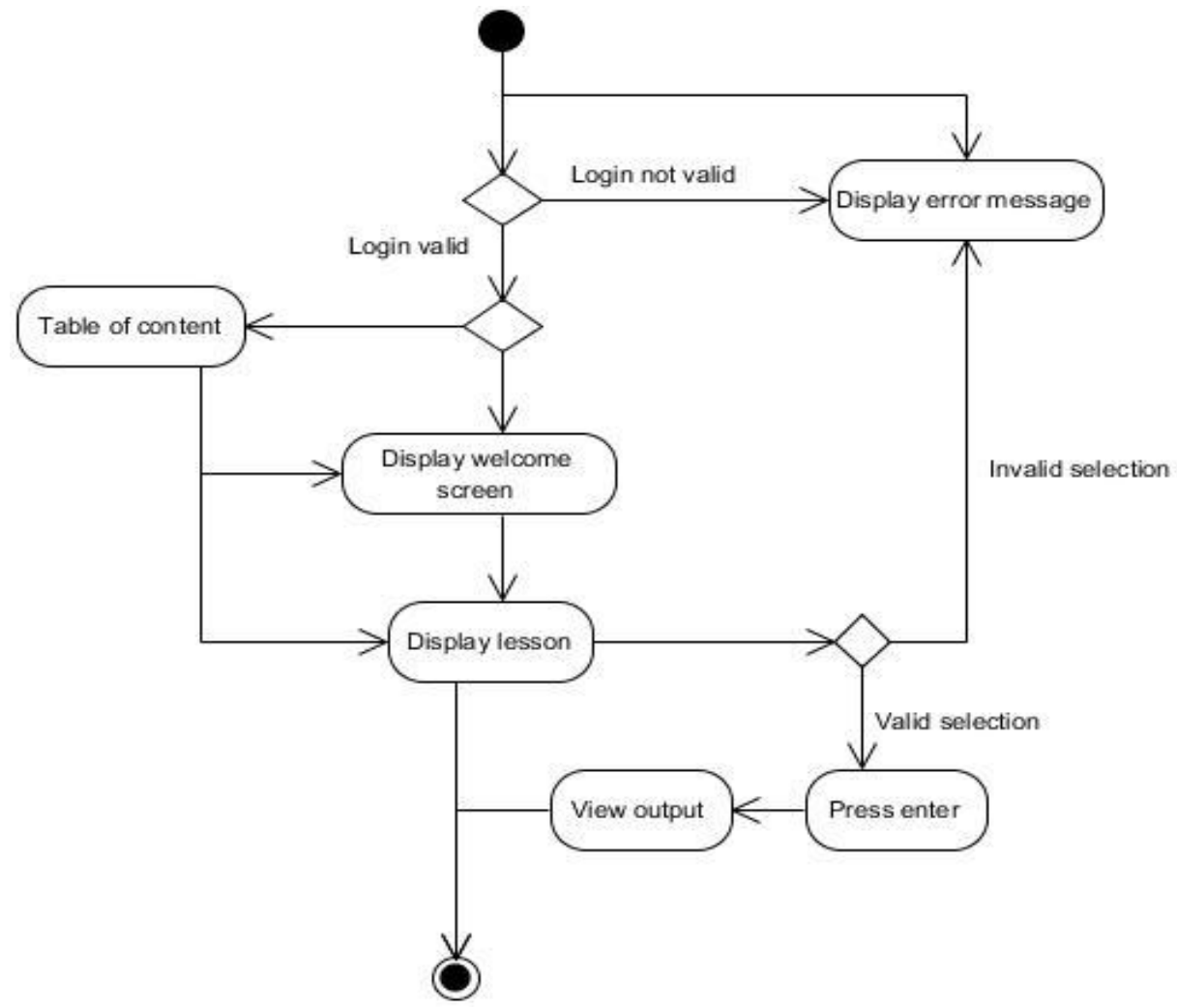

Figure 3: Activity Diagram for the Hausa learning system 


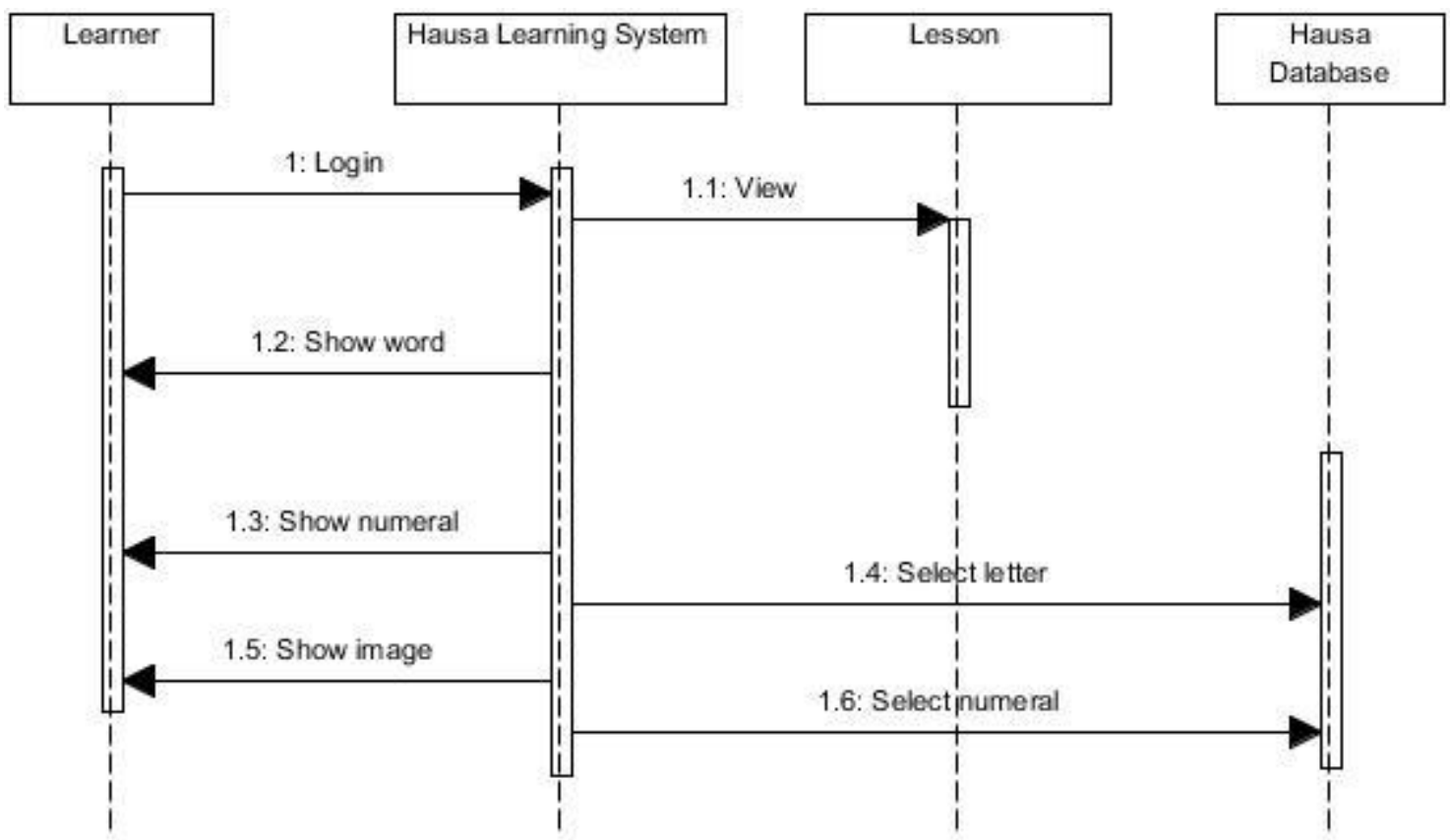

Figure 4: Sequence Diagram for the Hausa learning system

\section{IMPLEMENTATION}

The implemented Hausa learning system consists of various modules as well as sub modules and they are explained in detail below;

\begin{abstract}
Application launch interface
When the application is launched the welcome page is the select user type page. Here, users of the application/system are distinct i.e. a user is either the learner or an administrator and roles as well as tasks that can be performed by users on the system are solely dependent on this categorization. And a user cannot have access to the main page without selecting a user type. The figure 10 displays this page.
\end{abstract}

\section{New user interface}

Once a user type is selected as explained above a new user profile will need to be created for a first time user of the system else previously created user is selected and gains access to the main page. Figure 11 below displays the interface

\section{Alpha numeral interface}

This interface allows the user to make a choice between either alphabets or numerals and select as preferred. Figure 5 below depict this interface.

\section{Select letter interface}

This is the page that allows the user to select a desired letter from the alphabet and allows the user access to all words under a selected letter. Figure 6 below displays the interface and figure 7 show the selected letter page.

\section{Select numeral interface}

This is the page that allows the user to select a desired numeral from the numeric interface. Figure 9 displays this interface.

\section{Administrator login page}

The user type administrator has a special login platform that request for a username and password and this is to allow them access to certain roles that are unique to them alone and as well as manage certain task which includes;

I. Add Administrator: The administrator has a sole responsibility of adding new administrators and give them same privileges as the main administrator.

II. Edit Administrator's Profile: Any of the administrators can edit each of their profile.

III. Add New Words: The administrator can add new words to each letter of the alphabet as well as add new numerals.

IV. Edit Words or Numeral: The administrator can edit previously added words or numeral.

V. Remove Words or Numeral: The administrator can remove previously added words or numeral.

VI. View History: The administrator has a privilege of viewing the history of each of the users; all words and numerals viewed with their dates and this is solely for assessment purpose. 


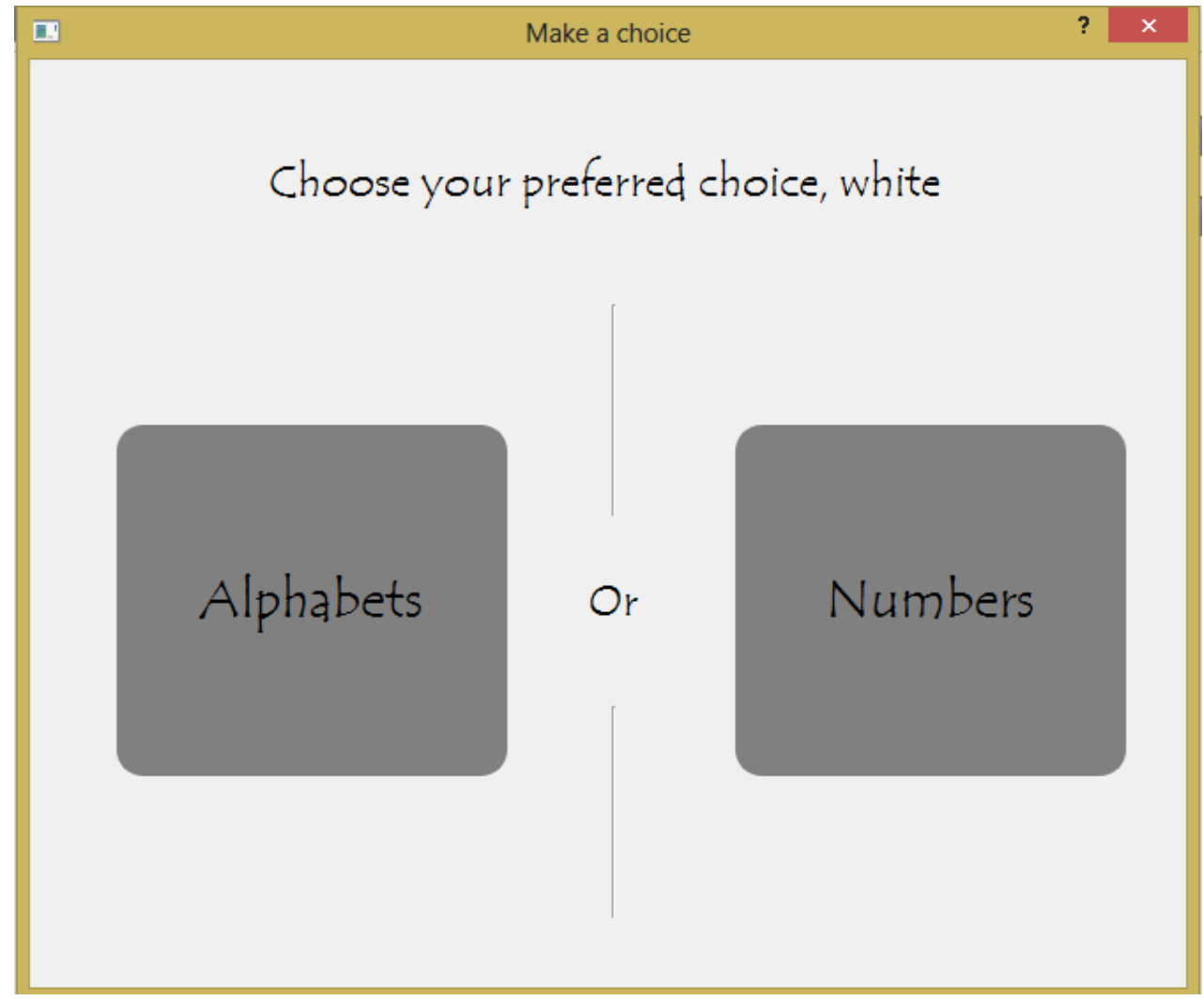

Figure 5 : Hausa Interactive Learning System User Interface

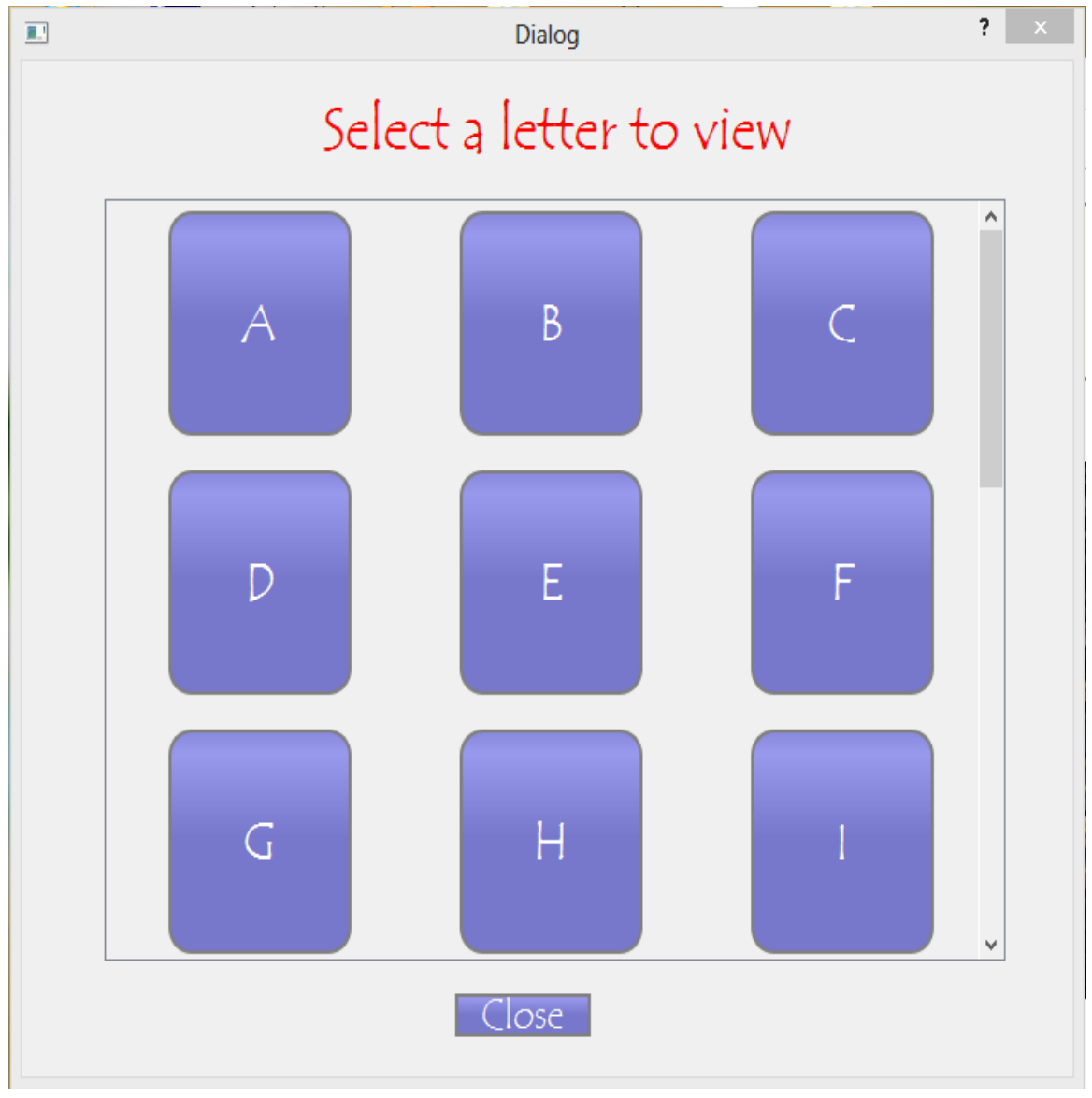

Figure 6: The Hausa Language Alphabets (user interface) 


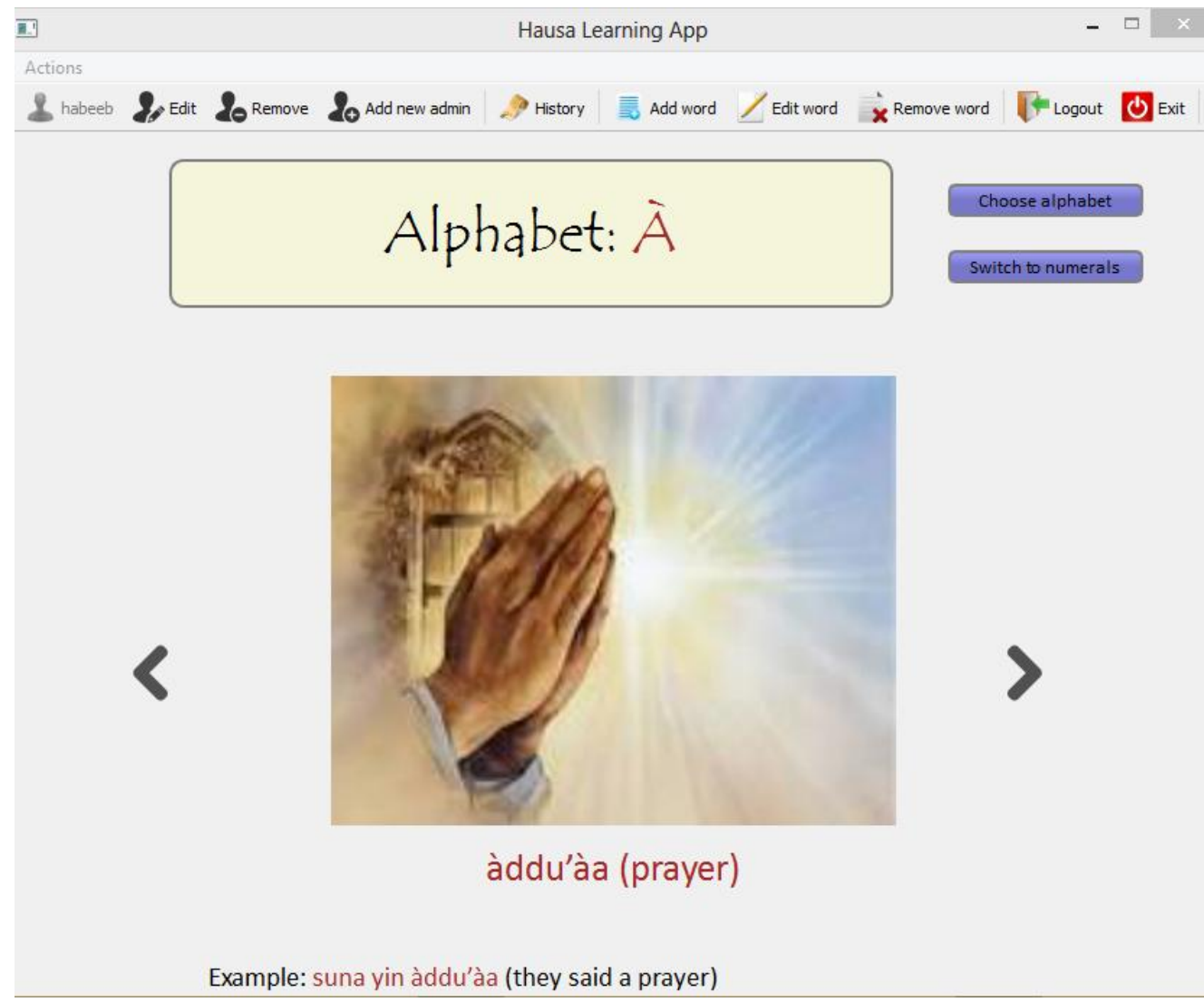

Figure 7: System Sample Output 1

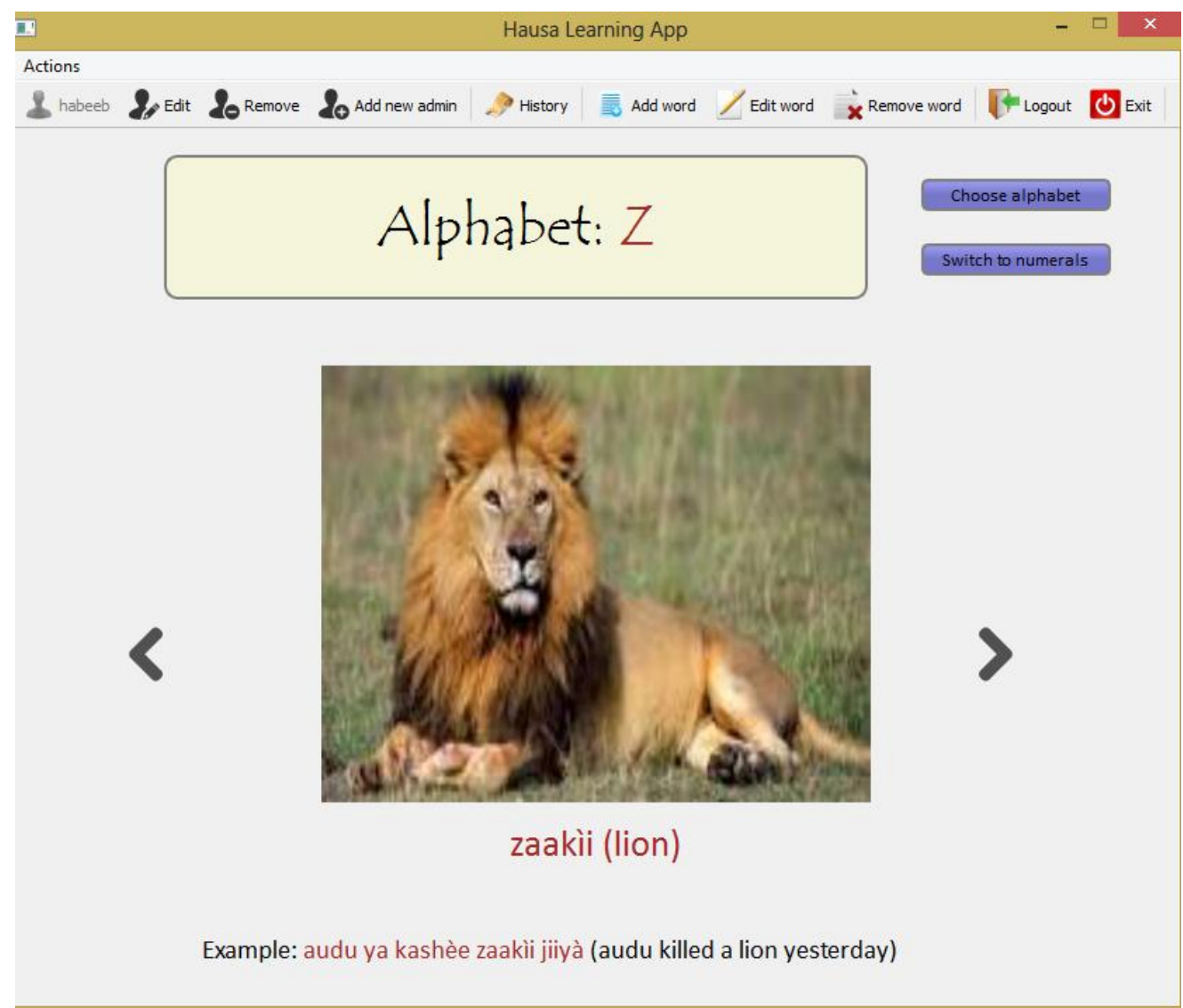

Figure 8: System Sample Output 2 


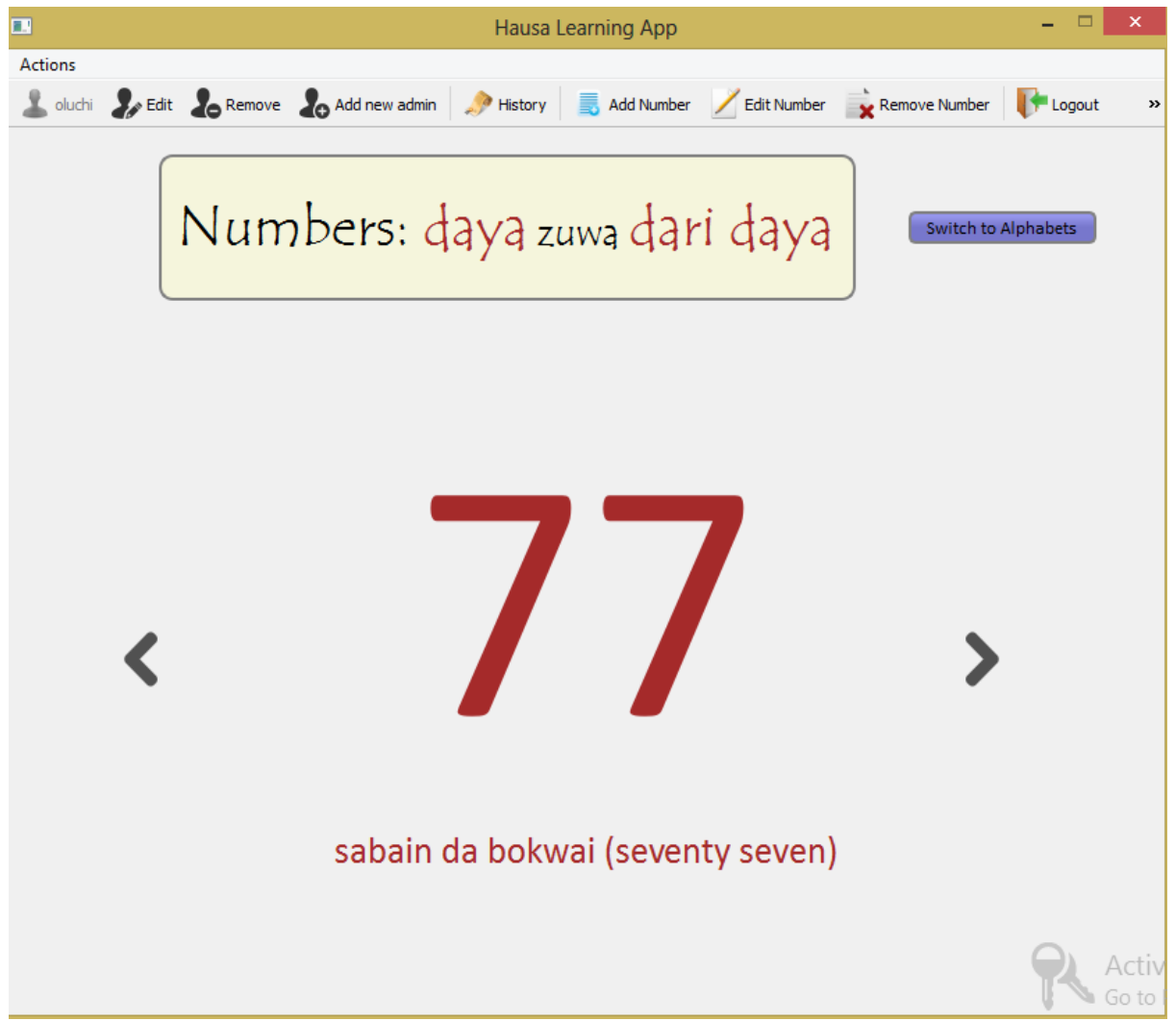

Figure 9: Numeral Output Interface

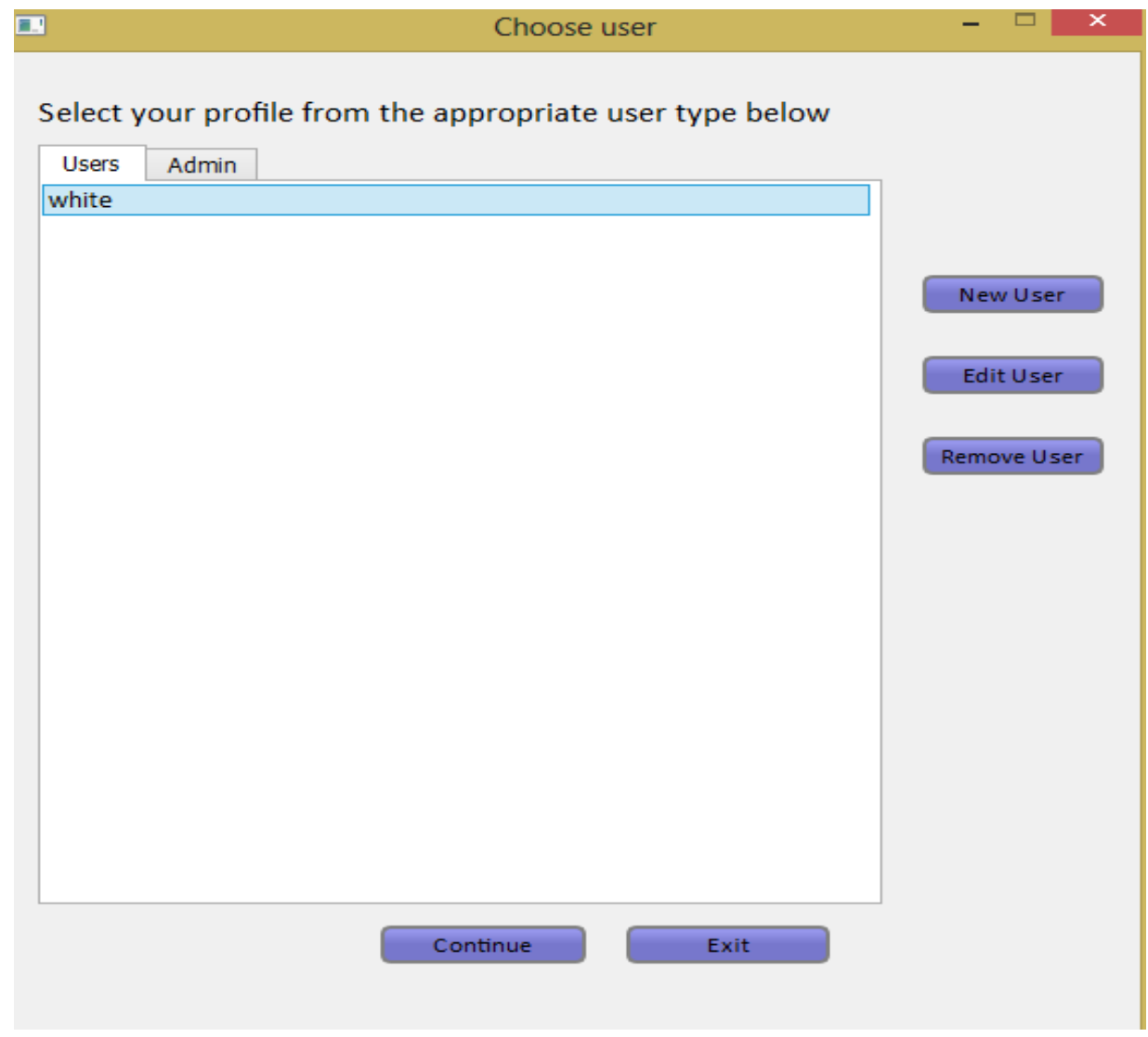

Figure 10: User type Interface 


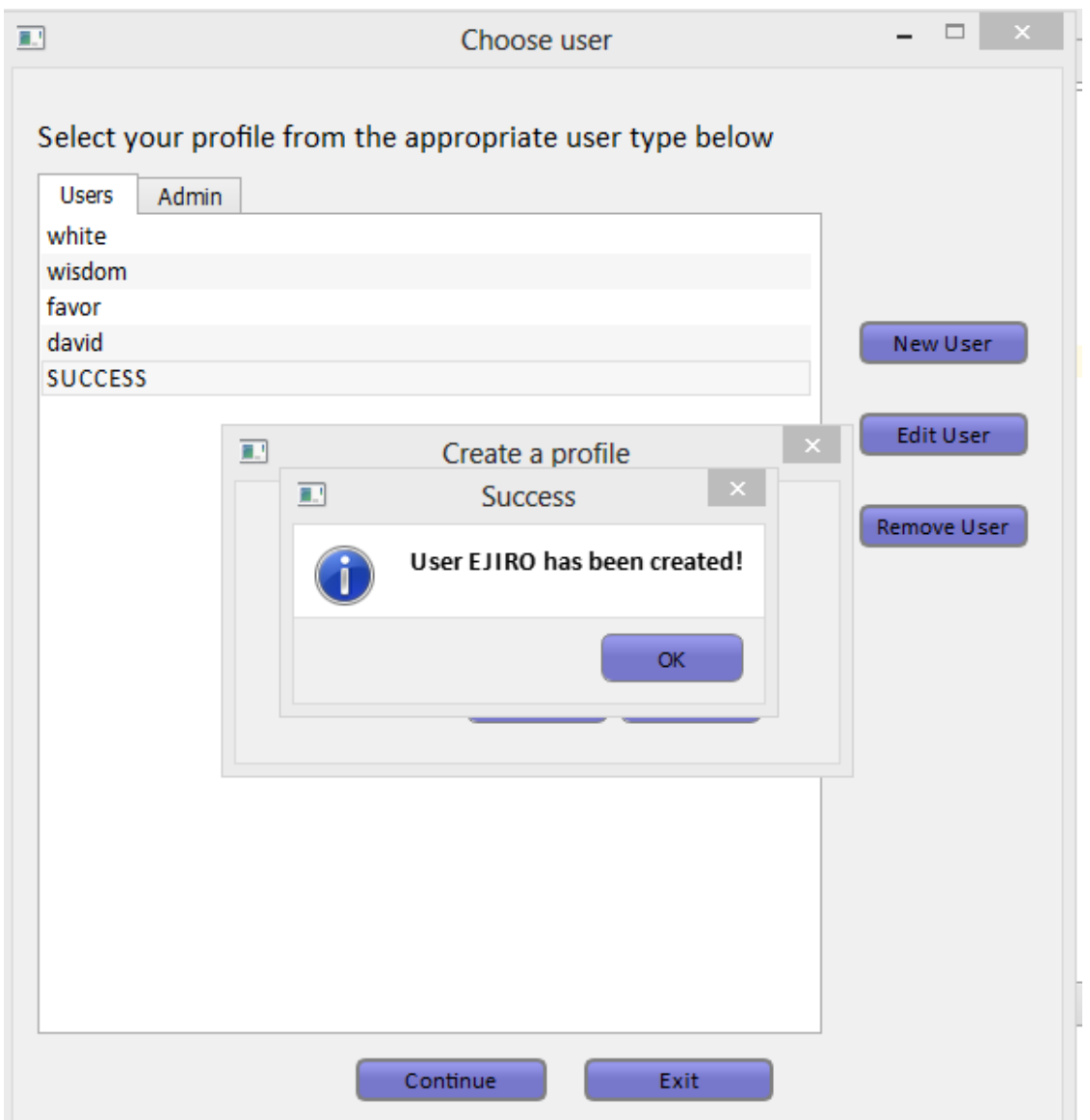

Figure 11: New User Interface

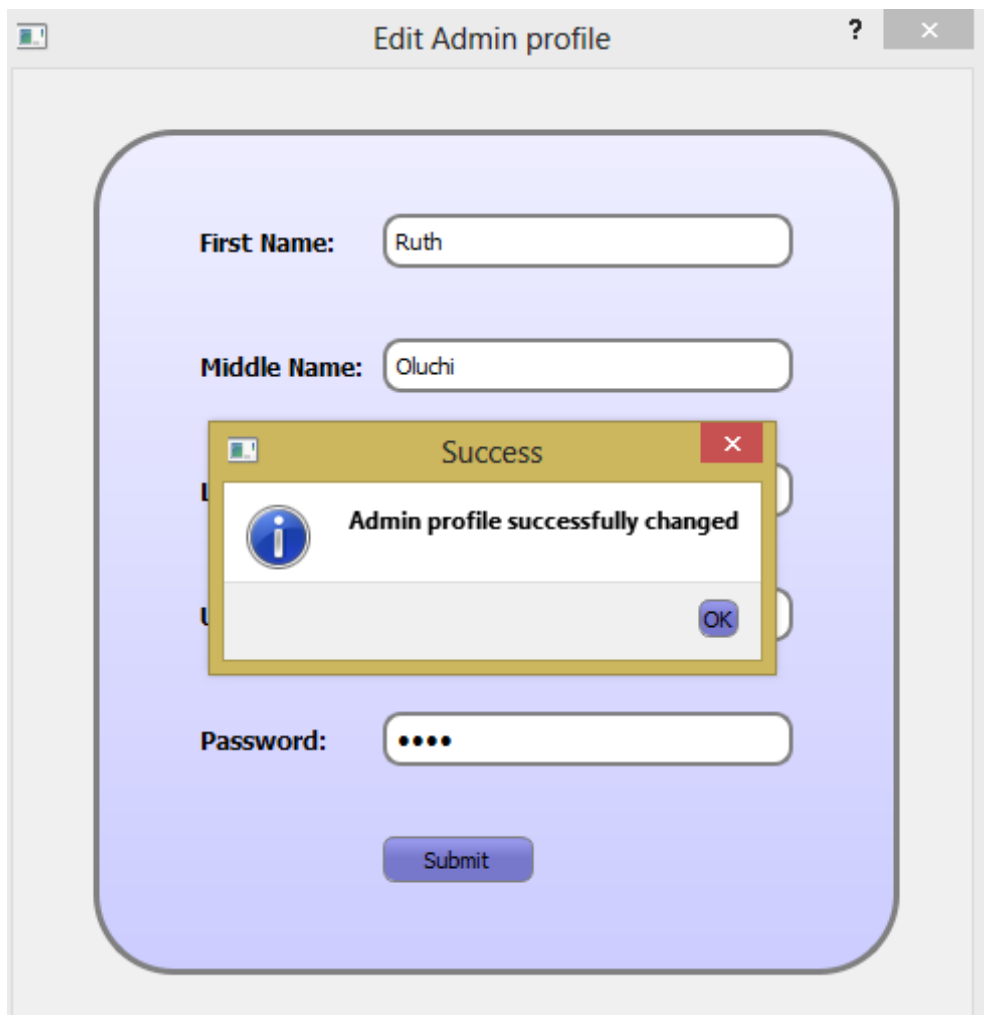

Figure 12: Admin Edit profile Interface 


\section{CONCLUSION}

Language learning systems especially for indigenious languages is an area that should be invested in heavily because of numerous benefits it offer. The presence of the Western culture which seem to have taken hold of our society (African society) in every area and even indigenous mother tongue is threaten. Hence, systems such as this would help keep langauges alive and this includes the language of case study and it will also help preserve as well as keep them away from possible extinction.

This great work would be advanced in the future by adding more features as well as functionalities such as audio to help learners to pronounce words correctly and with the right intonations and also an addition of lessons to test the learning abilities of leaners as well as to track the progress levels of the learners as well as to serve as progress and impact metric for the developed learning system.

\section{REFERENCES}

[1] Y. F. Lan and S. M. Huang, "Using Mobile Learning to Improve the Reflection: A Case Study of Traffic Violation," Educational Technology \& Society, vol. 15, no. 2, (2012), pp. 179-193.

[2] Herbert H. Clark, Using Language. Cambridge, UK: Cambridge press, 1996.

[3] Rafaeli, S. (1988). Interactivity: From new media to communication. In R. P. Hawkins, J. M. Wiemann, \& S. Pingree (Eds.), Sage Annual Review of Communication Research: Advancing Communication Science: Merging Mass and Interpersonal Processes, 16, 110-134. Beverly Hills: Sage.
[4] Biggs, J (1999) Teaching for Quality Learning at University, Society for Research into Higher Education and Open University Press, Buckingham.

[5] Jung, I, Lim, C, Choi, S and Leem, J (1998) Development of Teaching-Learning Models for WBI for Lifelong Education, policy paper, Korea Foundation for Research, Korea.

[6] Harasim, L, Hiltz, S, Teles, L and Turoff, M (1995) Learning Network: A Field Guide to Teaching and Learning Online, MIT Press, Cambridge, MA.

[7] Levy, Mike \& Glenn Stockwell. 2006. Call dimensions: Options and issues in computer-assisted language learning. Mahwah, NJ: Routledge.

[8] Adamu, M. 1984. "The Hausa and their Neighbours in the Central Sudan", In General History of Africa. IV: Africa from the twelfth to the sixteenth century. D.T Niane (ed), Californica: University of California Press.

[9] Gibanawa at Ethnologue (18 ${ }^{\text {th }}$ edition, 2015).

[10] Naroua, H., Salifou, L. (2014). 'International Journal of Computational Linguistics (IJCL), Volume (5): Issue (2): 2014

[11] Kosek, M. (2014). 'An Intelligent System for Learning Chinese with a Cognitive Model of the Learner'. M.Sc. Thesis, Department of Informatics, University of Oslo.

[12] Bialystok, E. (1997. The Structure of age: In search of Barriers to second language acquisition. Second Language Research, 13, 116-137. 